\title{
ARTE SIN TRADICIÓN, PRESENTES SIN ESPESOR SOBRE LA RELACIÓN ENTRE MODOS DE PRODUCCIÓN Y FIGURACIONES DE LA TEMPORALIDAD EN LAS POÉTICAS DE BELLEZA Y FELICIDAD
}

\author{
Marina Yuszczuk \\ UNMdP / CONICET
}

RESUMEN

En el contexto de la crisis económica durante la década del noventa en Argentina, los modos de producción, edición y circulación de la poesía se modificaron gracias a la proliferación de editoriales independientes. Belleza y Felicidad fue el proyecto más radical de los surgidos durante esta década, con modos de edición y experiencias poéticas como la performance que sustrajeron la poesía a la biblioteca - con la figura consecuente de una tradición que hunde sus raíces en el tiempopara proponerla como un objeto de rápida circulación y duración efímera. Este trabajo se propone poner en relación este modo de producción y edición con las nociones de temporalidad inscritas en los mismos poemas, donde se lee una experiencia del presente inmediata y perturbadora, bella y terrorífica, tensada entre la sensación de déjà vu y la inminencia del fin del mundo.

Palabras Clave: Poesía. Belleza y Felicidad. Editoriales independientes. Presente.
ABSTRACT

In the context of the economic crisis during the nineties in Argentina, the modes of production, edition and circulation of poetry changed due to the proliferation of independent publishers. Belleza y Felicidad was the most radical of the projects arising in that period, because it proposed modes of edition and poetic experiences such as performances, which subtracted poetry to the library -with the consequential idea of a literary tradition rooted in time- to treat poetry, instead, as an object of fast circulation and short duration. This paper intends to analyze the relation between modes of production and edition and the notions of temporality inscribed in the poems themselves, where it is possible to read an experience of the present immediate and disturbing, beautiful and terrifying, tensioned between the sensation of déjà vu and the imminence of the end of the world.

KEYwORDS: Poetry. Belleza y Felicidad. Independent publishers. Present.

Marina Yuszczuk es doctora en Letras por la Universidad Nacional de la Plata y becaria postdoctoral en la Universidad Nacional de Mar del Plata. 


\title{
ARTE SIN TRADICIÓN, PRESENTES SIN ESPESOR SOBRE LA RELACIÓN ENTRE MODOS DE PRODUCCIÓN Y FIGURACIONES DE LA TEMPORALIDAD EN LAS POÉTICAS DE BELLEZA Y FELICIDAD
}

\author{
Marina Yuszczuk
}

\begin{abstract}
Desde el 70 todo lo que pasa es irreal dijo, un poco cansado porque venía de una fiesta en la que habían bailado mucho para despedir al mundo.

Cecilia Pavón, El festival de las lágrimas

Todo lo que hacen

ya fué hecho

ustedes son parte de un

experimento, igualmente son muy capaces $\mathrm{y}$ tenemos fe en ustedes.
\end{abstract}

Fernanda Laguna, Samanta ${ }^{1}$

Belleza y Felicidad (ByF) designa al mismo tiempo un lugar de encuentro, una editorial y un grupo de escritoras, que a fines de los noventa y principios del nuevo siglo se caracterizó por englobar distintas prácticas como la poesía, las artes plásticas y la performance. Si bien el sello editorial sigue publicando hasta el presente, entre los años 1999 y 2007 Belleza y Felicidad funcionó además como galería de arte independiente en un local del barrio de Almagro, en la ciudad de Buenos Aires, donde había también una tienda de libros y materiales para artistas plásticos, se realizaban performances y lecturas de poesía, y se editaban revistas y plaquetas. ${ }^{2}$ Las poetas que llevaron adelante el

\footnotetext{
${ }^{1}$ Los errores ortográficos y tipográficos están en el original.

2 Fernanda Laguna describe las actividades realizadas en ByF y el origen del nombre: "Realizamos encuentros de poesías [sic], muestras de arte, recitales de música; es un lugar de experimentación artística, vendemos libros de editoriales independientes, discos también independientes y obras de arte, materiales para artistas, pinturas, telas, etc. y también tenemos una editorial propia, llevamos más de veinticinco libros publicados. Se han realizado improvisaciones musicales con computadoras, fue un ciclo que se llamó 'Juventud clandesina'* y fue un encuentro entre artistas alemanes y argentinos. Realizamos desfiles de modas y
} 
proyecto, Fernanda Laguna y Cecilia Pavón (acompañadas de cerca por Gabriela Bejerman), fueron reconocidas objetivamente como grupo literario - tal vez el único que verdaderamente fue percibido y pareció funcionar como tal en los noventa- ${ }^{3}$ porque si bien no hubo manifiestos ni programas explicitados, el nombre del espacio y la editorial, puesto en relación con las poéticas allí elaboradas, operó como una especie de consigna. De hecho, parte del reconocimiento externo como grupo se debió a la elección del nombre, que funcionó en buena medida como programa estético ( $y$ que fue relativamente polémico para otros productores del campo en el contexto de los noventa, al proponer lo "bello" como bandera al calor del resurgimiento de los debates sobre poesía y política que se dio a fines de la década y después de la crisis del 2001). ${ }^{4}$

Aunque este artículo se centra en la producción poética publicada bajo el sello Belleza y Felicidad, las prácticas del grupo se ampliaron para incluir a la performance, al tiempo que el local del barrio de Almagro albergó como dijimos varias muestras de plástica, lecturas de poesía, recitales y fiestas. Este carácter multidisciplinario es relevante porque trama las poéticas que despliega el grupo, y modifica en algún punto la relación con la propia literatura.

espectáculos teatrales. Se realizan dos exposiciones por mes con artistas, algunos conocidos y otros que hacen su primera muestra. En este momento se exhibe La Crista, es una gran instalación hecha por un grupo de internas del penal de Ezeiza. Nos identificamos con lenguajes contemporáneos y con artistas que expresan su inquietud por los tiempos que nos toca vivir. [...] Cuando comenzamos en 1999 éramos dos las que estábamos con este proyecto y se nos ocurrió 'Belleza y felicidad' porque es en resumen lo que todo ser humano busca y desea y podían conseguirlo aquí adquiriendo las cosas que en ese entonces vendíamos." LAGUNA, Fernanda. De todo un poco. El Abasto, Buenos Aires, n. 50, oct. 2003. Entrevista a Judith Villamayor.

3 Por grupo literario entendemos, como señala Bourdieu, "un instrumento de acumulación y de concentración del capital simbólico (con la adopción de un nombre, la elaboración de manifiestos y de programas y la instauración de ritos de agregación, como los encuentros regulares)." BOURDIEU, Pierre. Las reglas del arte. Génesis y estructura del campo literario. Trad. Thomas Kauf. Barcelona: Anagrama, 1995, p. 398.

${ }^{4}$ Sobre Belleza y Felicidad y otros segmentos de la poesía y las artes plásticas de los noventa, se suscitaron debates en torno a la oposición arte político/arte banal, uno de cuyos ejemplos es la mesa redonda "Arte rosa light y arte Rosa Luxemburgo", realizada en el Malba el 12 de mayo de 2003 y en la que participaron Roberto Jacoby, Ana Longoni, Andrea Giunta y Magdalena Jitrik. Las ponencias que conformaron este encuentro pueden leerse en Ramona. Revista de artes visuales, Buenos Aires, n. 33, p. 52-91, jul./ago. 2003. Por último, Cecilia Palmeiro lee esta concentración de ByF en la banalidad de las minucias cotidianas como un modo transgresor de "prescindencia frente a la cosa pública" que se impuso como parte de la "problemática vigente" (BOURDIEU, Pierre. Las reglas del arte, op. cit., p. 361) del campo poético a fines de los noventa y principios del 2000 (PALMEIRO, Cecilia. Desbunde y felicidad. De la cartonera a Perlongher. Buenos Aires: Título, 2011, p. 181). 
En efecto, las poéticas de Belleza y Felicidad se armaron desde una ideología de la inespecificidad o de aquello que Reinaldo Laddaga llama "una cultura posdisciplinaria de las artes", que vendría a reemplazar a la cultura moderna centrada en la noción de "obra" y en la creencia en la importancia de dicha obra en tanto soporte de una verdad. ${ }^{5}$ En efecto, las primeras plaquetas de ByF presentan algunos rasgos que Laddaga señala como propios de las "comunidades experimentales" posdisciplinarias, dado que se trataba de escribir y publicar casi simultáneamente y de ediciones efímeras que no condicen con las ideas tradicionales de "obra" y "biblioteca".

Los textos, entonces, funcionan dentro de estas modalidades de la práctica artística que los determinan formalmente, por lo cual el primer desplazamiento con respecto a la tradición vigente en el período está dado por este modo de publicar y hacer circular la poesía que acabamos de describir. ${ }^{6}$ Sucede que en un contexto de crisis económica en el que la mayoría de las editoriales independientes de poesía recurrieron a formatos pequeños y artesanales para reducir los costos de publicación, pero manteniendo sin embargo la idea de libro como objeto de colección con cierto nivel de diseño y concebido para ser conservado, las ediciones de Belleza y Felicidad fueron las más radicales del campo poético al reducir al mínimo la distancia temporal entre escritura, publicación y circulación de los textos. Cecilia Palmeiro encuentra un origen popular en estos modos de edición que fueron tomados por Laguna, Pavón y Bejerman de un viaje que hicieron a Salvador de Bahía, en el nordeste de Brasil, en el que descubrieron la literatura de cordel. Allí las poetas encontraron que algunos negocios vendían pequeños libritos colgados de una cuerda junto con todo tipo de chucherías, una modalidad de circulación literaria que desacraliza la literatura porque la pone junto con otros objetos baratos

${ }^{5}$ LADDAGA, Reinaldo. Estética de la emergencia. Buenos Aires: Adriana Hidalgo, 2006, p. 2122.

${ }^{6}$ Consideramos que hasta fines de la década del noventa, hay mayormente consenso en el campo poético con respecto al valor de la tradición literaria y a cierta ideología de la escritura como trabajo que requiere pulido, corrección, y ciertos saberes específicos que incluyen el conocimiento de partes de la tradición con las que dialoga la propia obra. Esta ideología es la que sostiene, a grandes rasgos, la publicación que más peso tuvo en la difusión y promoción de nuevos poetas, el Diario de poesía, que comenzó a publicarse en 1986 bajo la dirección de Daniel Samoilovich. De hecho, una de las figuras centrales en el armado de tradición que hizo el Diario fue Ezra Pound, quien sostiene algunas de estas ideas en $E l A B C$ de la lectura y se constituyó en un modelo para varios de los poetas que produjeron en el período. 
como un artículo de mercado por demás accesible. ${ }^{7}$

Sin embargo las plaquetas realizadas por Belleza y Felicidad entre 1999 y el 2000 a partir de esta idea se acercan más a los fanzines de las diversas subculturas del rock (esas revistas ejecutadas artesanalmente, con rapidez y a bajo costo, para ponerlas a circular dentro de ciertos grupos) que al formato de libro pensado para conservarse en una biblioteca. Se trata de publicaciones de pocas páginas, editadas en fotocopias sobre papel o cartón, con ilustraciones cuyos autores generalmente no se consignan. ${ }^{8}$ Otro dato relevante es que muchas de ellas presentan errores de tipeo y faltas ortográficas; además el diseño es mínimo, y da toda la sensación de un objeto hecho de forma rápida y descuidada. Muchos de los dibujos están realizados a mano, con trazos desprolijos, o a veces con figuras muy simples hechas por computadora. Algunas plaquetas contienen un solo poema, aunque una parte menor consta de varios textos y constituye casi un pequeño libro. La prioridad está puesta en el hacer y en la circulación rápida y eficaz de los poemas; de hecho, se trata de un formato que presenta un carácter efímero, y que parece negar tanto la fetichización del libro como objeto como la posibilidad de conservación en una biblioteca. A este respecto, Ana Mazzoni y Damián Selci señalan que los nuevos formatos de las publicaciones independientes deben tomarse como una mediación imprescindible entre las poéticas y el crítico. Los autores observan a propósito de las ediciones de Belleza y Felicidad y de buena parte de las publicaciones independientes de los noventa:

Están hechas de fotocopia, de modo que lo más probable es que en diez años la impresión desaparezca y nos quede un libro en blanco. Los libros fueron hechos para conservar conocimiento, cultura o lo que fuere, pero estos libritos en cambio son más parecidos a preservativos — su fórmula no es "yo conservo", sino más bien "úselo y tírelo". En cierto modo nos indican que son o serán basura. ${ }^{9}$

No parece que el planteo pueda aplicarse a todas las ediciones independien-

\footnotetext{
7 PALMEIRO, Cecilia. Desbunde y felicidad, op. cit., p. 172-173.

${ }^{8}$ En este sentido, las publicaciones de Belleza y Felicidad se diferencian de otras editoriales como Vox o Siesta, que muchas veces ilustraban sus libros con obras de artistas plásticos contemporáneos, pero explicitaban el nombre del artista en la primera página. El gesto supone, en este caso, reconocer la colaboración entre artistas de distintas disciplinas y constituir a su vez el libro en objeto de diseño.

9 MAZZONI, Ana y SELCI, Damián. Poesía actual y cualquierización. En FONDEBRIDER, Jorge (comp.). Tres décadas de poesía argentina. 1976-2000. Buenos Aires: Libros del Rojas, 2006, p. 263.
} 
tes de los noventa en Argentina por igual, puesto que las publicaciones de otras editoriales muy difundidas como Siesta o Vox presentan, es cierto, un formato de libro miniaturizado, pero que se propone como objeto de diseño coleccionable (en parte porque se pone el acento en las colaboraciones entre artistas plásticos y escritores, como dijimos). Pero en el caso de las plaquetas de Belleza y Felicidad - aunque no es seguro que corresponda llamarlas "libritos"- es pertinente lo señalado por Selci y Mazzoni, no sólo por razones materiales como el descuido en la edición, la falta de mención de los artistas que diseñan las tapas o las fechas de publicación en algunos casos. También hay una ideología distinta sobre la poesía que se desprende de esta clase de soporte, y que se enuncia de manera explícita en un texto llamado "A la mayoría de los poetas" que figura en una revista, Ceci y Fer, editada por Laguna y Pavón en el 2004: "Antes de salir esta revista, ya vendió más ejemplares/ que todos tus libros durmiendo en los estantes de las librerías que/ además pagaste vos mismo para publicar./ Qué triste estar solo en tu casa, y que nadie te lea!" ${ }^{10}$ Como se ve, construir un público y asegurarse la llegada a ese público mediante un soporte accesible y de rápida circulación es una prioridad. Además, la revista es representativa del tipo de mezcla de materiales que conforma la poética de Belleza y Felicidad por cuanto en ella se yuxtaponen, de manera des-jerarquizada, textos poéticos, e-mails, frases manuscritas que ocupan toda la página como un grafitti, letras de canciones pop traducidas y conversaciones por chat.

Ese carácter efímero del objeto que se percibe tanto en las plaquetas como en la revista Ceci y Fer entra en consonancia con la temporalidad efímera que proponen los mismos poemas, a veces concebidos más para la presentación en público que para la lectura privada y silenciosa que constituye el modo de consumo de la literatura moderno y burgués por excelencia. Con respecto a esto, si bien en la década del noventa se incrementó ampliamente la práctica de las lecturas públicas de poesía como modo de difusión de los textos, en el caso de Belleza y Felicidad ésta no se circunscribió a la simple puesta en voz de los textos sino que se acercó más a la performance y la puesta en escena, como lo muestra el testimonio de un poeta y crítico literario que asistió a un espectáculo de este tipo:

${ }^{10}$ LAGUNA, Fernanda y PAVÓN, Cecilia. A la mayoría de los poetas. Ceci y Fer. Buenos Aires: Belleza y Felicidad, p. 49, 2004. 


\begin{abstract}
En Bahía Blanca el año pasado se organizó un recital de Fernanda Laguna, Cecilia Pavón y Bejerman: la sala apagada, salen ellas vestidas con una especie de pijamas o camisones blancos, descalzas. Se sientan en un rincón lleno de almohadones y papeles afiche blancos desparramados en el piso; al rato encienden una gran cantidad de velitas que depositan sobre esos papeles. Una música muy suave e indefinida acompaña este clima espectral, y comienzan a leer. Mientras una lo hace, las otras dibujan sobre los papeles. Los poemas, más que textos aislados, parecen estar dialogando entre sí, respondiéndose unos a otros como en un encuentro de amigas. ${ }^{11}$
\end{abstract}

En este tipo de performance, donde el cuerpo usado como material para la obra se convierte en signo ${ }^{12}$, la persona del poeta determina fuertemente la recepción de los textos, y la escena funciona, según expondremos, como representación de un modo de circulación particular de los textos poéticos dentro de un grupo definido. Por eso el estatuto de los textos debería pensarse a la luz de estas prácticas que se caracterizan por el cruce de lenguajes, y donde el cuerpo es "puro presente, realidad absoluta, presentación sin más" antes que investirse de algún tipo de carácter representativo. ${ }^{13}$

Estas prácticas que rodean y constituyen la producción de Belleza y Felicidad modifican el modo de concebir la poesía, que ya no puede pensarse sólo en relación al campo literario sino a los intercambios más amplios de una comunidad interdisciplinaria de artistas en la que el énfasis está puesto más en el "hacer" - y hacer en un "ahora"- que en el producto final. Al mismo tiempo, la velocidad de producción, publicación y circulación pone en entredicho la idea hegemónica de poesía como trabajo artesanal sobre el lenguaje que demanda tiempo y corrección, y que atraviesa toda la modernidad. Al contrario, como señalábamos junto con Laddaga, lo que se pone en cuestión es la noción de "obra", o al menos se la amplía para incluir en ella tanto la producción textual como sus modos de circulación y presentación en público, a la vez que todas estas instancias adquieren un carácter efímero.

Además, la modalidad de publicación descrita está en consonancia con la construcción que estas poetas realizan de sí mismas como artistas "ingenuas". Según Bourdieu, en cada momento del campo hay una problemática vigente

${ }^{11}$ ORTIZ, Mario. Hacia el fondo del escenario. Vox Virtual, Bahía Blanca, n. 11/12, jul. 2002.

${ }^{12}$ GLUSBERG, Jorge. El arte de la performance. Buenos Aires: Ediciones de Arte Gaglianone, 1986, p. 39.

${ }^{13}$ Cf. ROSENBAUM, Alfredo. Performance, cruce de lenguajes y provocación. Análisis del ciclo de performance en expotrastiendas 2007. Revista KEPES, v. 5, n. 4, p. 217-235, ene./dic. 2008. 
de la que los escritores se hacen cargo, ya sea para rechazarla o plegarse a ella, y que delimita el espacio de lo pensable. ${ }^{14}$ Pero hay artistas que ignoran (o simulan ignorar) la historia específica del campo y la lógica de su juego. Bourdieu se refiere a este grupo como "artistas ingenuos", y señala que se caracterizan por una producción que intenta acatar las normas más convencionalizadas de lo que se entiende como "literario" dentro de ámbitos no especializados, e incluso aquellas que han sido abandonadas hace tiempo por otros artistas consagrados. ${ }^{15}$ En Belleza y Felicidad esta noción del "artista ingenuo" se activa por la recuperación, no tanto de la tradición literaria sino de sus derivaciones más bien degradadas en la cultura de masas, y puede verse por ejemplo en el uso de un léxico desprestigiado en la poesía de los noventa pero que tiene su pervivencia en otras manifestaciones culturales tales como los posters, las tarjetas de celebración que se comercializan en los quioscos o los diálogos de las telenovelas. Además, en este caso emplearemos el término "ingenuos" sumándole otro sentido, puesto que aquí se construyen voces adolescente e infantiles que pueden caracterizarse de ese modo. Pero, como dijimos, esta idea de "artista ingenuo" debe pensarse como el armado de una figura que permite parodiar los valores consagrados en el campo, dado que las poetas de que nos ocupamos tenían cierto capital cultural específico (Pavón y Bejerman completaron la carrera de Letras en la UBA y Laguna es Profesora

${ }^{14}$ BOURDIEU, Pierre. Las reglas del arte, op. cit., p. 361.

${ }^{15}$ Bourdieu se refiere con esta denominación a una figura como la del Aduanero Rousseau, "descubierta" por un campo del que ignoraba las reglas, pero también, por ejemplo, a la correspondencia amorosa de las clases populares y su empleo de una retórica ya considerada obsoleta en el campo literario. Es interesante que al definir al artista ingenuo, el autor plantee cierta vinculación con una idea tradicional de literatura propia de la escuela primaria (porque como hemos visto, la producción de ByF puede relacionarse también con la tendencia denominada "escuelismo" en plástica y su modo de trabajar sobre el imaginario y la retórica escolares). Dice Bourdieu: "la poesía sigue encarnando todavía en nuestros días la idea que de la literatura se forman los consumidores menos cultos (sin duda debido a la influencia de la escuela primaria, que tiende a identificar la iniciación literaria con el aprendizaje de poesías). Como cabe comprobar mediante el análisis de un diccionario de escritores [...] los miembros de las clases populares y de la pequeña burguesía que empiezan a escribir tienen (salvo excepciones) una idea demasiado elevada de la literatura para escribir novelas 'realistas'; $y$, de hecho, su producción consiste esencialmente en poesías - muy convencionales formalmente- $[\ldots]$ ". BOURDIEU, Pierre. Las reglas del arte, op. cit., p. 363 (nota al pie). Entonces, dejando de lado la referencia a las "clases populares", que no es pertinente aquí, sí podemos decir que el gesto de acceder a la literatura desde otro lugar articula en Belleza y Felicidad esta idea "ingenua" de poesía que no está ni estaría presente de ningún modo en otros poetas de los noventa (sobre todo en aquellos que exhiben cierta conciencia histórica de los usos de la lengua en poesía) con el trabajo de pastiche sobre aquellas manifestaciones de esta misma idea ingenua de poesía que aparecen en los productos de la cultura de masas. 
Nacional de Dibujo y Pintura por la Escuela Nacional de Bellas Artes Prilidiano Pueyrredón). Esta idea de "ingenuos" también describe bien la posición ocupada por Belleza y Felicidad como grupo centrado en la práctica pero en el que mayormente se eludía la reflexión crítica e incluso la tendencia a tomar las teorizaciones sobre la escritura propia y ajena como parte de la condición de poeta que en otros casos se daba por sentada como un valor. ${ }^{16}$

A partir de esta figura del que no sabe escribir poesía, del poeta "analfabeto" por decirlo así, lo que se lleva a cabo es un gesto de tabula rasa, en escrituras que no retoman la tradición literaria sino que arman el poema como pastiche de estilos que incluye escrituras menores como el diario íntimo, las cartas y las formas del discurso sentimental de la cultura de masas, además de recursos como el uso de rimas y del pretérito perfecto y de términos altamente estilizados que denotan el esfuerzo por "escribir correctamente", mezclado con las faltas de ortografía que se conservan en la edición final, sobre todo en Laguna. De hecho en el poema Salvador de Bahía, ella y yo, Laguna comienza por decir: "Este es un cuento/ muy bonito/ y simple.// Es mi primer cuento/ es lo más largo/ que he escrito.// Mi proyecto ambicioso,/ mi consagración." ${ }^{17}$ Estos primeros versos, que resumen de manera absurda la carrera de un escritor -el primer cuento coincide con la consagración-, pueden leerse como parodia del ingreso institucional a la literatura e incluso de la tradición pensada en términos de "canon", sobre todo por la lista de "influencias" que se consignan a continuación: "He usado/ más palabras que nunca./ He imitado/ a grandes escritores/ como Bocaccio,/ César Aira,/ Clarice Lispector,/ Cecilia Pavón,/ Gabriela Bejerman/ y Paulo Coelho." La lista tiene un efecto cómico pero además deja en ridículo a la idea de tradición según la cual un poeta debería leer a Bocaccio antes que a sus más estrictos contemporáneos e incluso a sus amigos, al tiempo que burla las jerarquías que se recuestan en el prestigio de lo antiguo por el ingreso desafiante de los

\footnotetext{
${ }^{16}$ La mayoría de los poetas de los noventa no ejercieron la crítica literaria como sí lo hicieron, por ejemplo, Martín Prieto, Daniel García Helder y Fabián Casas en el Diario de poesía. Pero aún así, cuando se trataba de exhibir un grado de reflexión sobre la propia poética o sobre la poesía en general, la mayoría estaba dispuesto a hacerlo, dando por sentado que se trataría de una actividad que es intrínseca a la tarea del poeta, mientras que Fernanda Laguna remarca en varias oportunidades su desconocimiento de la poesía, la tradición o, como en este caso, las normas convencionales de escritura.

${ }^{17}$ LAGUNA, Fernanda. Salvador Bahía, ella y yo. Buenos Aires: Belleza y Felicidad, 1999. En el caso de las citas de plaquetas, no se consignan números de páginas puesto que las plaquetas no los tienen y en algunos casos constan solamente de un par de pliegos.
} 
amigos y contemporáneos como "grandes escritores". Más adelante en el mismo texto la autora se refiere al esfuerzo que tuvo que poner para escribir, bien distinto del "pulido" que funcionaba como valor en buena parte de las poéticas de los noventa, especialmente las vinculadas al Diario de poesía: "Fue difícil para mí/ mantener el hilo para que se entienda/ algo tan largo./ También me costó/ conjugar bien los verbos/ y encontrar los adjetivos apropiados." Más que una dificultad en el trabajo con la escritura, aquí se trata de construir una figura del que tiene dificultades en el manejo más básico y escolar de la lengua, al punto de que le cuesta conjugar los verbos. En Laguna sobre todo, lo que se pone en escena es un yo infantilizado que parece estar accediendo a la escritura poética por primera vez, sin un manejo fluido de las reglas más elementales, como lo muestran aquí las faltas de ortografía: "Ella se ha ido a Uruguay/ a travez de la frontera con la Argentina./ [...] La casa es de dos hambientes chicos." ${ }^{18}$

Esta figura de "poeta analfabeto" (en el sentido de que carece del capital cultural específico para la tarea literaria) impregna buena parte de la producción de Belleza y Felicidad, y habilita el simulacro de escribir como si fuera por primera vez, y decididamente, por fuera de lo legitimado institucionalmente como literatura. ${ }^{19}$ Lejos de plantearse la escritura como un oficio que supone

18 ídem, Cartas de amor. Buenos Aires: Belleza y Felicidad, 2000.

${ }^{19}$ Gabriela Bejerman y Cecilia Pavón en cambio presentan poéticas divergentes cuando publican en otras editoriales o en libros de poesía (y no plaquetas) más parecidos a la producción de los noventa que hemos analizado hasta aquí. Así, Bejerman por ejemplo procesa la escritura de Perlongher y de Marosa di Giorgio en un libro como Crin, donde el énfasis está puesto en la materialidad de la palabra en elaboraciones que detentan rasgos del neobarroco: "Cuando me seduzco en las melodías del piano de mi voz planeo sobre lagos turquesas y arena volcánica y pareciera entonces que nunca volveré a devorar carne, suelto alas, pájaros y adolescentes llorosos, todos se zambullen en el cielo aéreo o en el cielo acuático, y yo floto convertida en un puñado de plumas que se dispersan en la inmensidad." (Crin. Buenos Aires: Belleza y Felicidad, 2001, p. 31). También hay poemas de este libro que tematizan el funcionamiento del sentido en relación a la escritura ("siento que viene el sentido/ como una ola/ apenas llega/ la marea baja/ no sé si queda alguno/ en mí/ sólo hay colores", p. 18). Pero este tipo de escritura más autorreflexiva, impensable en Laguna como no sea bajo un gesto paródico o por lo menos ambiguo, ya estaba presente en algunos poemas de Bejerman publicados como plaquetas en Belleza y Felicidad: "no hay más prosa que la sintaxis rítmica del verso." (Judía. Buenos Aires: Belleza y Felicidad, 2000). Sin embargo, en este caso optamos por trabajar únicamente la producción en plaquetas de Belleza y Felicidad (con menciones ocasionales a otros libros) centrándonos en la figura de Fernanda Laguna puesto que su escritura y su construcción como poeta, en tanto constituyen la propuesta más radical de las nucleadas en Belleza y Felicidad, condicionaron el modo en que el grupo fue percibido desde el exterior, como lo demuestran los artículos de prensa citados anteriormente donde se lo criticaba a partir de rasgos presentes sobre todo en la obra de Laguna. 
un saber específico, los poemas publicados por Laguna, Pavón y Bejerman en este proyecto remiten en su mayoría a un mundo adolescente en el que un grupo de amigas cuentan sus aventuras, sobre todo sexuales y amorosas, y se dedican poemas unas a otras. Algunos textos de Fernanda Laguna contienen además una marca performática, porque remiten a una escena de lectura frente a un público: “- ¡Hola!/ Mi nombre es Samanta y/ he venido a este planeta/ a contarles un cuento" ${ }^{20}$; "Este es un cuento/ muy bonito y muy simple"21; "Les voy a contar una anécdota triste" ${ }^{22}$. En estos casos, los poemas parecen estar concebidos para ser presentados ante una audiencia y muchas veces, como sugieren estos versos, toman la forma de un cuento infantil leído ante un grupo de niños. ${ }^{23}$

La construcción del analfabeto adopta en este caso una modulación infantil que sustrae la poesía a las reglas de juego propias del campo en un momento dado, como señalaba Bourdieu, y tiene que ver como dijimos con hacer el gesto de escribir por fuera del campo literario, desde una concepción ingenua y escolar de la poesía. Asimismo, las faltas de ortografía ponen en escena la falta de capital cultural específico, y junto con el estilo remiten la escritura no al trabajo de un poeta que se concibe a sí mismo como tal, sino a los ejercicios escolares y la práctica de registro del diario íntimo. Efectivamente, muchos de los textos remedan el diario de una adolescente, por eso hay todo un campo semántico asociado a los sentimientos que se repite sin matices: "En casa tengo al osito-mono/ que me satisfacería bastante/ si no fuera tan parecido a un muñeco./ El amor se me revela de a pedacitos/ como un cristal facetado;/ un ojo, un brillo, una caricia, un cuerpo, un sonido,/ una sonrisa,/ etc.// Ay.../ El amor, el amor, el amor..." ${ }^{24}$ Los gustos que manifiesta el "yo" que habla en los poemas, así como su modo de relacionarse con los amigos y con los productos culturales de su preferencia, se caracterizan asimismo por la ingenuidad: “¿cómo será Madonna?/ Será buena y simpática/ ¿existirá?/ A mi me

\footnotetext{
${ }^{20}$ LAGUNA, Fernanda. Samanta. Buenos Aires: Belleza y Felicidad 1999.

${ }^{21}$ ídem, Salvador Bahía, ella y yo, op. cit.

${ }^{22}$ ídem, Licor de café (club de señoritas y señoras). Buenos Aires: Belleza y Felicidad, 1999.

${ }^{23}$ La voz de enunciación en los poemas de Belleza y Felicidad puede ser alternativamente infantil o adolescente, sin que resulte posible fijar una "identidad", puesto que se trata, como vimos en el capítulo anterior, de construcciones performáticas que eluden la posibilidad de ser fijadas en una u otra categoría. En este sentido, se acercarían más bien a la noción de sujeto no-unitario y nómade propuesta por Rosi Braidotti en Feminismo, diferencia sexual y subjetividad nómade. Trad. Gabriela Ventureira, María L. Femenías. Barcelona: Gedisa, 2004.

${ }^{24}$ LAGUNA, Fernanda. Poema IV. Buenos Aires: Belleza y Felicidad, 2000.
} 
gustan mis amigos/ que los puedo tocar,/ que me abrazan,/ me miran y yo siento/ su presencia en el corazón./ De Madonna me gusta "Like a virgen"/ "Open your Heart" y "Thief of hearts" / y alguna de sus bailarinas." ${ }^{25}$ En consonancia con esto, en Fernanda Laguna, pero también en Bejerman y Pavón, la relación con las amigas toma la forma del enamoramiento.

Lo mismo puede decirse de las plaquetas de Cecilia Pavón. Una de ellas, sin ir más lejos, lleva por título a fernanda (por Laguna) y otra se llama Gabriela, los hombres y yo (por Bejerman). El festival de las lágrimas, La euforia y Primer beso son los títulos de otras publicaciones, que remiten una vez más a un mundo de emociones tan intensas como efímeras similar al de Laguna. Tanto el amor romántico y la alegría -aunque sería más preciso hablar de euforiacomo la tristeza y la angustia, se presentan "sin que (las obras) parezcan rendirse ante la emoción más que como un concepto abstracto", según señala Marcos Livingstone a propósito de los cuadros pop de Roy Liechtenstein. ${ }^{26}$ Gabriela, los hombres y yo, por ejemplo, es un poema de Pavón dedicado a Bejerman en el que se cuentan las conversaciones telefónicas entre las amigas por la noche. El poema dice: "Sonrisas, sonrisas, sonrisas/ Gabriela, Gabriela, Gabriela/ ¿sos consciente?: la naturaleza ha nacido/ para mostrársete y nada más/Creo que el amor es un sueño que tienen/ tus animales." ${ }^{27}$ De nuevo, junto a un vocabulario acotado en el que se repiten términos como "sonrisa", "naturaleza", "amor" y "sueño", que formarían parte de un diccionario degradado y prácticamente ausente en el resto de las poéticas de los noventa, aquí aparece puesta de relieve la importancia de una operación que atraviesa estos poemas: la de nombrar, no sólo a las amigas poetas sino al grupo más amplio de novios, amigos y conocidos. Si bien se trata de textos que se ponen a circular dentro de una comunidad de artistas, las representaciones del intercambio de poemas y dedicatorias que hacen estas poetas remiten más a la práctica común de enviarse cartas y tarjetas que realizan las adolescentes entre sí (una apreciación similar puede leerse en la descripción que Mario Ortiz hace de una performance de Belleza y Felicidad que figura más arriba). Los poemas, por eso mismo, adoptan un carácter doble: son publicados y vendidos como literatura, pero a la vez hacen el gesto de ser cartas, páginas de

\footnotetext{
${ }^{25}$ ídem, La señorita. Buenos Aires: Belleza y Felicidad, 1999.

${ }^{26}$ LIVINGSTONE, Marcos. Una tecnicultura gloriosa. En Arte pop. Muestra del Museo Nacional Reina Sofía. Madrid: Electra, 1992, p. 19.

${ }^{27}$ PAVÓN, Cecilia. Gabriela, los hombres y yo. Buenos Aires: Belleza y Felicidad, sin fecha.
} 
diarios íntimos, pequeños cuentos para ser contados entre amigos (de ahí que estén plagados de guiños al interior del grupo). Desde esta perspectiva cobra sentido el diseño que, como dijimos, remite por momentos a la apariencia de los cuadernos escolares y las tarjetas que se regalan las adolescentes. Esta idea de la poesía como objeto de intercambio entre un grupo de amigas, un intercambio que se realiza siempre en presente y desconoce por completo el pasado literario, concuerda con las representaciones de un tipo de escritura no institucionalizada ni profesionalizada que estas poetas construyen en sus textos.

Como puede verse, la producción de Belleza y Felicidad representa un cambio de paradigma en relación a los valores vigentes en el campo poético de fines de los noventa en todos sus aspectos: en primer lugar, porque la figura de poeta ingenuo supone el abandono de la vinculación entre poesía y crítica (unida a la reflexión sobre el lenguaje) que sostenían la mayoría de los contemporáneos, y también porque aquí el gesto de tabula rasa con respecto a la tradición reside en el empleo de materiales degradados y desprestigiados, asociados fuertemente a lo infantil y adolescente, y a un culto de los sentimientos que proviene de sectores de la cultura de masas y de ningún modo de la tradición literaria. Además, la ideología de la inespecifidad que mencionamos al principio alcanza también al lenguaje, que ya no se concibe como instrumento de comunicación o como objeto sobre el que se trabaja, y ni siquiera como un elemento socialmente connotado. Se trata por el contrario de un lenguaje sin espesor, en el que no se ahonda desde una búsqueda del sentido; antes bien, el procedimiento que caracteriza a los poemas de Belleza y Felicidad es la repetición, que tiene el efecto inverso de sustraer de las palabras su carga histórica y semántica y que parece dejarlas lisas, brillantes y vacías.

Así, el lenguaje se asimila más que nunca a las superficies de los objetos de la cultura tecnificada, y puede ser motivo de fascinación para un sujeto pero en todo caso no mantiene ningún vínculo referencial con lo que otros poetas señalaban como "realidad" en sus textos. Es por eso que Pavón, al contar un cuento con un vocabulario que remite por momentos a los cuentos de hadas (como sugiere el uso del término "personas malvadas") puede decir:

A la puerta, donde contábamos el dinero, venían personas malvadas que nos querían robar, pero teníamos la plata escondida por todo el cuerpo, Fernanda y yo, 


\begin{abstract}
los billetes eran nuestra segunda ropa y nadie nunca nos quitaba nada. Era como volar sobre el dinero, poseer todo el dinero del universo para repartirlo entre los pobres. ${ }^{28}$
\end{abstract}

El texto pone en escena una fantasía, en la que términos como "los pobres" o "dinero" (en un uso por otra parte altamente artificial) ya no tienen correspondencias con un referente social sino que se convierten en pura superficie de un lenguaje que se lee como cita de discursos previos, ya sea el de los cuentos o las telenovelas. Así, a fuerza de repetición y de usar las palabras de una manera plana que las vuelve casi abstractas ("la tristeza", "el amor", "los pobres") parecería alejárselas de la experiencia para convertirlas en puro significante vaciado de sentido, una operación que encuentra su figura en el momento en que las emociones y las palabras mismas se convierten en ondas, imágenes, pantallas.

Porque tanto la imaginación como las emociones adoptan formas tecnológicas en Laguna, que en La señorita sueña con organizar una revolución pero se pregunta, "Revolución ¿de qué?", y acto seguido se imagina esta utopía difusa, desprovista de contenido (y por supuesto de toda connotación histórica) y en clave tecnificada: "Sí una revolución.../ Siento la presencia del deseo del amor/y me entrego como en un video". Más adelante en el mismo poema, lo que se pone en escena es la versión tecnificada también - pero no sofisticada, sino al contrario- de las emociones y hasta de la propia idea de "alma":

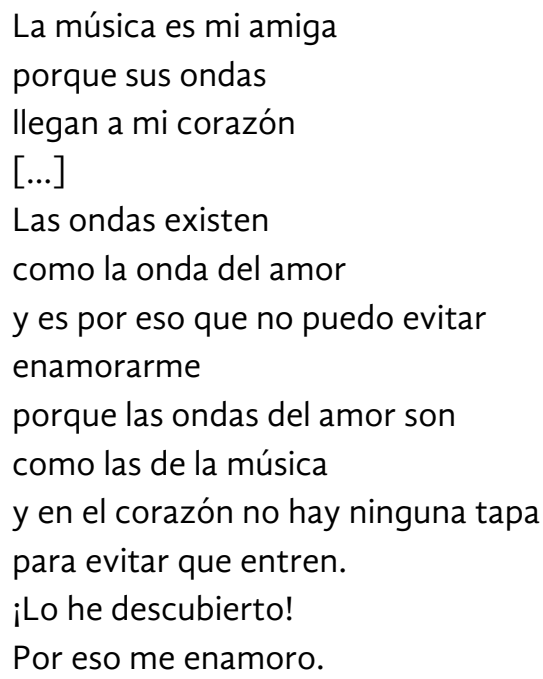

${ }^{28}$ ídem, a fernanda. Buenos Aires: Belleza y Felicidad, 2000. 


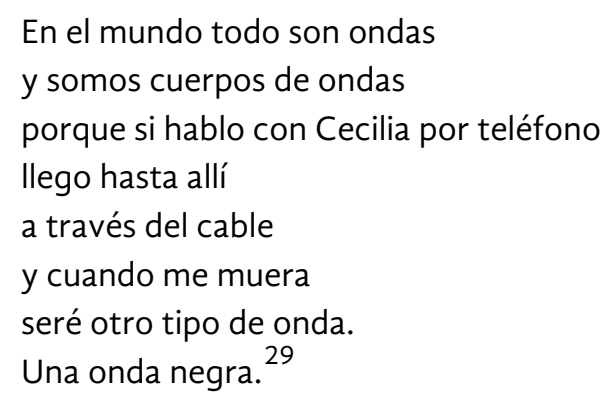

En este caso lo que se imagina es la desmaterialización de los cuerpos, y hasta el "yo" se asimila a las ondas eléctricas en su versión más simple y cotidiana, más banal (las ondas del teléfono).

En Poema IV, la que habla dice que está enamorada de una foto: "Yo sé muy bien que esa foto no tiene vida/ (...) Pero en realidad/ creo que amo la foto en general./ Amo el papel brillante,/ esa suavidad rozando mis labios./ En la intimidad de la noche/ la ilumino con una vela/ y siento al verla vibraciones muy especiales" ${ }^{30}$. El amor, en este caso, no reclama como objeto algo "vivo", como dice el propio texto, sino que se concentra en los brillos de la foto impresa, en la textura del papel, que se presenta incluso como objeto erótico, y no en la imagen que contiene el soporte. Dicho de otro modo, la foto no se percibe como representación sino como objeto real, y es eso lo que se ama. En Amigas, un cuento sobre cuatro mariposas que viven "En un jardín muy lindo", aparece una computadora en medio de ese jardín nada natural "y era mentira/ que necesitaba electricidad/ y que dependía del hombre./ Ella era libre/ porque lo deseaba/ y la tierra era su alimento/ agua y abono" ${ }^{31}$. También se dice que las mariposas "se reflejaban/ en la pantalla/ y ponían videos de Madonna". En la pantalla de ese objeto tecnológico aberrante que tiene comportamiento vegetal se fusionan las mariposas con la figura del ícono pop, y esta imagen puede valer como figura del poema y de su operación con el lenguaje. En este caso, la palabra "mariposa" que deviene reflejo (no de la realidad, puesto que estos usos están lejos de la mimesis) como continuidad de la superficie verbal en la superficie brillante y tecnificada del monitor de una computadora. Al mismo tiempo que usan el lenguaje de modo no representativo, los poemas ponen en escena una fascinación por el objeto técnicamente reproducible y por las imágenes que adopta incluso matices religiosos, y que

\footnotetext{
${ }^{29}$ LAGUNA, Fernanda. La señorita, op. cit.

30 ídem, Poema IV, op. cit.

31 ídem, Amigas. Buenos Aires: Belleza y Felicidad, 1999.
} 
se suma a la fascinación por las propias emociones.

Fredric Jameson se refiere a esta experiencia de los sujetos en relación a la tecnología como un nuevo "sublime tecnológico", donde la exaltación que en otros tiempos se daba frente a "lo otro" (es decir, lo irrepresentable) encarnado por la naturaleza, la divinidad o la propia tecnología de las máquinas de producción se desplaza ahora hacia las máquinas de reproducción, es decir, las computadoras y la televisión, que constituyen la parte experimentable de una red más amplia de poder y control imposible de representar o representarse. ${ }^{32}$ $Y$ que, como es de imaginarse, supone una nueva experiencia del tiempo, centrada en lo inmediato. Por eso los textos de ByF, aunque podrían tildarse de "irreales" sin más, ponen en escena una nueva experiencia del sujeto en relación a la tecnología, que fusiona incluso las imágenes técnicamente reproducibles con las imágenes mentales. En efecto, en Los celos no ayudan, la culpa tampoco (Autoayuda) el brillo de las imágenes aparece asociado a la creencia: "Yo deseo ser feliz/ [...] Y al acostarme/ soñar imágenes preciosas/ con mucho brillo/ y desear creer en ellas." ${ }^{33}$ Esta serie de sentido que se arma entre imágenes, felicidad y creencia habilita la idea de que hay un nuevo tipo de sublimidad e incluso de sacralidad en las imágenes - las mentales pero también las imágenes tecnificadas-, que en ocasiones pueden ser intercambiables, así como en este poema el sueño adopta el carácter brillante que antes se atribuía a la foto.

En César Aira y Cecilia Pavón, Laguna describe un "momento de iluminación" en el subte - de nuevo, como en el caso del teléfono, una experiencia cotidiana que remite a la vida en una gran ciudad. Se trata de un instante de "realidad extrema" que se describe en estos términos: "La situación en el subte/ ese momento de iluminación/ donde la inspiración/ o la realidad extrema/ se mete dentro de los pulmones/ y de allí va a la sangre." ${ }^{34}$ En este caso, la realidad extrema y la irrealidad se confunden totalmente, especialmente porque la "iluminación" puede referirse tanto a un instante de lucidez mental o espiritual como a las luces artificiales del transporte público. Se trata por otra parte de un momento que no anuda en sí mismo tiempos heterogéneos sino que no remite a nada fuera de sí mismo, y se impone al sujeto como

\footnotetext{
${ }^{32}$ JAMESON, Fredric. El posmodernismo o la lógica cultural del capitalismo avanzado. Trad. José Luis P. Torio. Buenos Aires: Paidós, 1992, p. 79-86.

${ }^{33}$ LAGUNA, Fernanda. Los celos no ayudan, la culpa tampoco (Autoayuda). Buenos Aires: Belleza y Felicidad, 1999.

${ }^{34}$ ídem, César Aira y Cecilia Pavón. Buenos Aires: Belleza y Felicidad, 1999.
} 
una sustancia que se inyecta en el cuerpo. Por eso la fusión entre espiritualidad y técnica, que produce un momento alucinatorio propio de la experiencia cotidiana de viajar en una metrópolis, es total. El poema sigue hablando de este estado, al que denomina "trance" y que hace decir al sujeto: "Adoro a todos, / amo a todos,/ no me importa nada".

Para Fredric Jameson este tipo de estados tienen su fundamento en el punto de indecidibilidad entre realidad y fantasía que implica la "ruptura de la cadena significante" (término del que se vale el autor para describir las obras posmodernas). ${ }^{35}$ Esta ruptura deja librado al sujeto a "una experiencia puramente material de los significantes o, en otras palabras, a una serie de meros presentes carentes de toda relación en el tiempo". Además, esto va a acompañado de sensaciones de irrealidad: "inmensidad sin límites, luz brillante, y la lisura y el lustre de las cosas materiales" ${ }^{36}$, que se aplican perfectamente al poema de Laguna que acabamos de citar. Sin afirmar de ningún modo que las poéticas analizadas deban pensarse a partir de la categoría de "posmodernidad" ${ }^{37}$, lo cierto es que lo descrito por Jameson coincide con las sensaciones que ponen en escena los poemas de ByF. Porque aquí hay un presente intensificado que, según Jameson, puede producir angustia y sensación de pérdida de realidad, pero también "puede imaginarse en términos positivos como la prominente intensidad intoxicadora o alucinatoria de la euforia" ${ }^{38}$. En los poemas de Belleza y Felicidad, éste es precisamente el signo que adopta la experiencia del puro presente, experiencia que a su vez aparece ligada a la vida en la gran ciudad y a la interacción del sujeto con la tecnología.

Así, la "realidad" se menciona y redefine de modo recurrente en los poemas de Laguna y Pavón, que pueden tanto decir "la bella realidad" (véase Salvador Bahía, ella y yo, donde también se dice que es la Virgen quien hace a la que

${ }^{35}$ De hecho, Jameson toma esta noción de la descripción lacaniana de la esquizofrenia, pero en este caso no haremos alusión a este término por las connotaciones de normalidad/patología que supone.

${ }^{36}$ JAMESON, Fredric. El posmodernismo o la lógica cultural..., op. cit., p. 64-65.

${ }^{37}$ El término "posmodernidad" con el que Jameson intenta vincular un estado de la cultura con la situación del capitalismo avanzado en las grandes metrópolis nos parece poco apropiado para pensar las poéticas de ByF, si bien coinciden en muchos rasgos con lo descrito por este autor, puesto que se trata de un fenómeno cultural de una ciudad donde ciertos rasgos que podrían pensarse como posmodernos (sobre todo después de la implementación de las políticas neoliberales de la década del noventa) coexisten en un entramado particular con modos de hacer y condiciones culturales propias de los países no globalizados -no debe olvidarse, además, que las poéticas que aquí abordamos surgen en torno al derrumbe de la era neoliberal que supuso la crisis del 2001.

${ }^{38}$ JAMESON, Fredric. El posmodernismo o la lógica cultural..., op. cit., p. 66. 
escribe "enamorarme,/ entregarme,/ escribir y ver/ la bella realidad") como afirmar que semejante cosa no existe más. Tal es el caso en El festival de las lágrimas, un poema de Pavón en el que se imagina el fin del mundo con una mezcla de miedo y euforia:

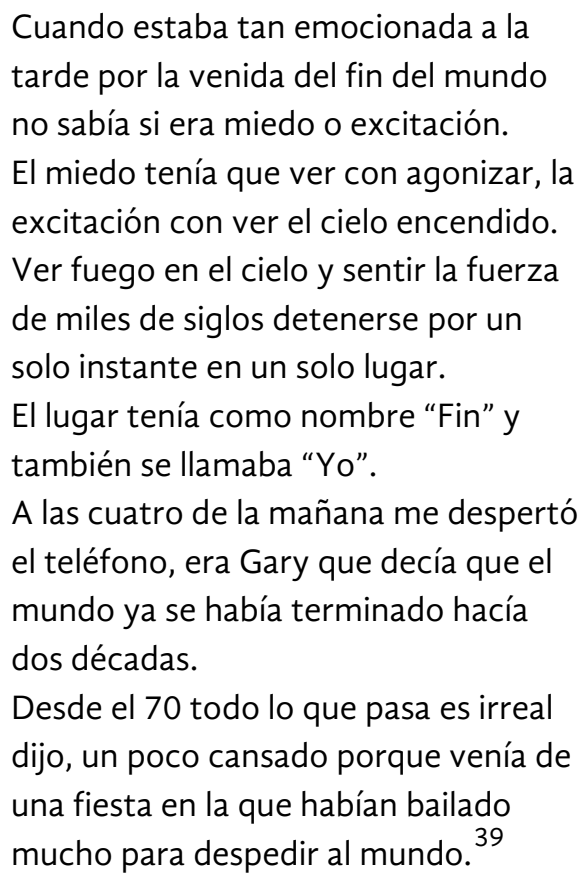

Aquí, el fin del mundo -y del tiempo- coincide con el fin del "Yo" (prefigurado en el grupo de amigas que intercambian poemas y que se nombran en ellos al punto de volverse casi intercambiables), ese "Yo" con mayúsculas que ha sido siempre el centro del discurso poético moderno como lugar de enunciación que organiza la subjetividad. La pérdida del yo como límite, temido y a la vez deseado, se hace presente también en las preguntas de Pavón en a fernanda: "llegará la locura alguna vez? la convulsión? la epilepsia?" 40

Entonces, lo que se lee en los poemas de Laguna y Pavón publicados en el marco del proyecto Belleza y Felicidad es la fascinación con el brillo de las imágenes que alcanza también al modo de experimentar el lenguaje como superficie. Ellas conforman una nueva realidad desrealizada que tal vez no sea otra cosa que el lenguaje convertido en imágenes planas, que brillan pero nada reflejan. Por eso las emociones y las mismas palabras que las nombran, que también son objeto de adoración, se convierten a su vez en imágenes, reflejos

${ }^{39}$ PAVÓN, Cecilia. El festival de las lágrimas. Buenos Aires: Belleza y Felicidad, sin fecha.

40 ídem, a fernanda, op. cit. 
en una pantalla o en la superficie de una foto, al punto de que en Amigas, el poema de Laguna antes citado, se dice que "Las pantallas/ también saben dar/ y recibir amor". Lo importante es que debido a este modo de experimentar la tecnología, las imágenes y el lenguaje, la tensión entre alta cultura y cultura de masas que organiza la modernidad es dejada de lado junto con las nociones modernas de sujeto y de historia, sin ningún tipo de nostalgia. Con este cambio de paradigma, lo que se modifica también, además de las concepciones sobre el lenguaje, la poesía y la figura del poeta (aunque como intentamos demostrar, todos estos cambios están relacionados), es el modo de experimentar el tiempo. Porque como señalaba Jameson, la ruptura de la cadena significante supone que el sujeto se fragmenta y queda librado a "una serie de meros presentes carentes de toda relación en el tiempo". Bajo esta condición, no hay posibilidad de construir una vinculación entre pasado, presente y futuro que unifique al sujeto y por lo tanto de continuidad a su experiencia a lo largo del tiempo. Así, Cecilia Pavón enuncia en un poema que

El pasado no es doloroso, el pasado es lindo
cuando voy en el colectivo, ex novio, qué lindo es recordarte
siento que navego por el mar de autos y que mis percepciones son
ligeras
Si el amor es lo único que puede darle contenido a la vida,
qué lindo es haber vivido y ahora estar liberada [...].

Si el texto puede plantear un pasado sin dolor y desprovisto de conflicto, y hasta "lindo" (es decir, sin heterogeneidad y sin matices), es porque lo que surge aquí no es una memoria que presentifique una experiencia vivida, sino que se trata más bien de un recuerdo en alguna medida despersonalizado (de ahí que el poema contraste el "haber vivido" con el "ahora estar liberada", como si nada hubiera quedado del pasado más que un recuerdo tan "ligero" y en alguna medida ajeno como las percepciones de la ciudad a las que se alude).

Esta desconexión entre pasado y presente en la mente del sujeto, de hecho, anula la posibilidad de que exista la historia, y este dato está estrechamente vinculado con el juicio sobre la realidad que se plantea en el poema de Pavón ya citado, El festival de las lágrimas: "Desde el 70 todo lo que pasa es irreal/ dijo, un poco cansado porque venía de/ una fiesta en la que habían bailado/

${ }^{41}$ ídem, ¿Existe el amor a los animales? Buenos Aires: Siesta, 2001, p. 39. 
mucho para despedir al mundo." Sin embargo aquí este comentario sobre el fin de la realidad - que constituye casi una reflexión teórica- está puesto en boca de otro personaje llamado Gary, mientras que la que enuncia el poema dice "No sé, le respondí, yo nací en el 73 no/ he vivido tanto tiempo". En Samanta de Fernanda Laguna se presenta una variante de esta idea que adopta la forma del déjà vu: "Todo lo que hacen/ ya fue hecho/ ustedes son parte de un/ experimento,/ igualmente son muy capaces/ y tenemos fe en ustedes." Para Paolo Virno, el déjà vu se define como una repetición puramente ilusoria, aparente: se cree haber vivido algo que en cambio está sucediendo por primera vez. ${ }^{42}$ Según el autor, este es un estado de ánimo extendido que caracteriza las formas de la vida contemporánea, ligado al tema filosófico del fin o la detención de la historia (que puede leerse en la afirmación de que "Desde el 70 todo lo que pasa es irreal" del texto de Pavón), y en este caso podemos ligarlo con el carácter ilusorio de la "realidad" que se construye en los poemas.

Virno recurre a Bergson para decir que en esta forma de experiencia prevalece la impresión de que el futuro está cerrado ${ }^{43}$, y esto se relaciona con la presencia recurrente del motivo del fin del mundo (vinculado en ocasiones con el motivo de la fiesta como, de nuevo, en El festival de las lágrimas de Cecilia Pavón) en los textos de ByF y en publicaciones posteriores de las mismas autoras. Así, en la novela Presente perfecto de Gabriela Bejerman ${ }^{44}$, el relato se refiere a una fiesta en la casa de una baronesa. En un cuarto significativamente poblado de pantallas, la baronesa monitorea su propia fiesta por televisor, y está preocupada porque el fin de la fiesta será también el fin del mundo. ${ }^{45}$ En un momento este mismo personaje, aburrido de la fiesta, quisiera poner la mente en blanco (volver a "la pantalla blanca", dice en realidad el texto) para que las imágenes de la fiesta la impresionen y encanten por primera vez. Ese adelgazamiento del tiempo tiene como consecuencia que el deseo de una vuelta al origen coincida con la experiencia del fin del mundo

\footnotetext{
${ }^{42}$ VIRNO, Paolo. El recuerdo del presente. Trad. Eduardo Sadier. Buenos Aires: Paidós, 2003, p. 15.

43 ibídem, p. 17.

${ }^{44}$ BEJERMAN, Gabriela. Presente perfecto. Buenos Aires: Interzona, 2004, p. 40.

${ }^{45}$ Es interesante observar, como variante de esta idea, que un relato de Fernanda Laguna publicado bajo el seudónimo de Dalia Rosetti donde se cuentan las desventuras de una chica neurótica e insegura que se siente fracasada, siempre en clave cómica, termina con el suicido de la protagonista, que en el momento de morir se siente feliz y satisfecha. Ver Dalia Rosetti, Me encantaría que gustes de mí. Buenos Aires: Mansalva, 2005, p. 44.
} 
como una inminencia que asedia de modo recurrente, por más que al final de esta novela breve, que tiene lugar a la mañana siguiente de esa noche de fiesta, los invitados que quedaron desayunen juntos y se diga que "creaban el ambiente perfecto para presentir que todo puede siempre continuar."

Lo que ponen en escena estos textos es una experiencia del tiempo constituida por "puros presentes", para decirlo en términos de Jameson, o de un tiempo fragmentado que ya no se concibe como linealidad -incluso hecha de interrupciones y caídas como en la perspectiva dialéctica de Benjamin-, sino de bloques de sensaciones y estados autónomos que apenas guardan conexión entre sí. Esta percepción del tiempo se vincula con lo planteado por Virno, para quien el déjà $v u$, como fenómeno propio de la sociedad del espectáculo caracterizada por una inclinación a "mirarse vivir" 47 , hace percibir el presente como repetición ilusoria de un pasado que nunca existió. Sin embargo, aunque acordamos con la descripción que hace Virno de la experiencia del tiempo, no puede decirse como lo hace este autor - probablemente con cierto prejuicio a favor de las nociones de temporalidad modernas que permitirían vincular presente y pasado para proyectar el futuro-que este modo de experimentar el presente inhabilite al sujeto para la acción ${ }^{48}$, o en todo caso habilitan otro tipo de acciones que tienen que ver con la inmediatez, hasta con cierta urgencia. Porque Belleza y Felicidad fue un proyecto que puso el énfasis en el hacer y que abrió todo un espectro de actividades y poéticas nuevas, como lo muestra su vinculación posterior con la editorial Eloísa Cartonera y su multiplicación en tantos nuevos proyectos autogestionados que en la actualidad se extienden a diversos países de Latinoamérica y Europa. ${ }^{49}$ En efecto, aunque prevalezca la sensación de que el futuro está cerrado, tal vez nos encontremos frente a un nuevo tipo de sensibilidad que compensa en intensidad lo que le falta, o parece faltarle desde la ideología moderna todavía dominante, en capacidad de proyectarse en el tiempo.

\footnotetext{
${ }^{46}$ BEJERMAN, Gabriela. Presente perfecto, op. cit., p. 76.

${ }^{47}$ VIRNO, Paolo. El recuerdo del presente, op. cit., p. 63-64.

48 ibídem, p. 16.

${ }^{49}$ Cf. PALMEIRO, Cecilia. Desbunde y felicidad, op. cit., p. 212.
} 